4 Niemela RK, Hakala M. Primary Sjogren's syndrome with severe central nervous system disease. Semin Arthritis Rheum. 1999;29(1):4-13

\section{AB0121 CYTOSTATICS EFFECT ON THE DEVELOPMENT OF MALIGNANT AND LYMPHATIC PROLIFERATIVE FORMATIONS DURING SJORGEN?S DISEASE (SS)}

MV Simonova, VI Vasiliev, NS Shornikova. Department of Rheumatology, Institute of Rheumatology of RAMS, Moscow, Russia

10.1136/annrheumdis-2001.304

Background Treatment of rheumatological pts by alkylating cytostatics is undoubtedly of positive effect on the process of the disease but in a long term can stimulate the development of neoplasms and lymphatic proliferative diseases.

Objectives To detalise the degree of risk of above mentioned pathologies in SS pts who for a long time took low doses of chlorobutin or cyclophosphane - from 5 to 15 years.

Methods In the 1st group of 300 pts aged 15-75 years (46.4 (1.7) with disease duration of 5-25 years (8.7(1.9) 200 pts took $5 \mathrm{mg}$ of Prednisolone daily, $1.8 \mathrm{~g}$ for a year, $0.9-1.8 \mathrm{~g}$ for the subsequent years combined with chlorobutin by $2 \mathrm{mg}$ daily; 720 $\mathrm{mg}$ for a year and $360-720 \mathrm{mg}$ for the next years. $100 \mathrm{pts}$ had cyclophosphane by $200 \mathrm{mg}$ twice a month i.v.; $4.8 \mathrm{~g}$ for a year and in the next 5 years yearly dosage was $2.4-4.8$ g. 2nd group included 100 female pts who took only Prednisolone according the same scheme. $3 \mathrm{~d}$ group of 100 female pts had no antirheumatic therapy. Age of pts in 2nd and 3d groups was 18-78 years (46.2(2.3) and disease duration of 4-26 years (9.2(2.1). Minimal frequency of blastomas and lymphatic proliferative diseases $(1.6 \%)$ development was in the 1st group (pseudolymphoma in $1 \mathrm{pt}$, lymphoma - 2 cases, cancer of stomach in 1 and of skin in $1 \mathrm{pt})$. In the group treated only by GCS 7 cases of lymphoma were found and 1 case of stomach cancer (8\%). Pts who had no antirheumatic therapy had 7 pseudolymphomas 9 lymphomas, 2 cases of Valdenstrem crioglobulinemia, 2 cases of stomach cancer and 1 pulmonary cancer (21\%). Out of them pseudolymphomas and lymphomas were diagnosed in $18 \%$.

Results

Conclusion Long term of taking of low doses of cytistatics (chlorobutin, cyclophosphane) combined with low doses of GCS does not promote the development of blastoma process in SS pts and decreases the frequency of transformation of the disease in malignant lymphomas.

\section{FRI0212 CORRELATION BETWEEN HISTOPATHOLOGICAL FINDINGS, SERO-IMMUNOLOGICAL PROFILE AND MARKERS OF DISEASE ACTIVITY IN SICCA SYNDROME}

M Benucci, A Mannoni, F Li Gobbi, U Serni. Rheumatology, I. O. T. ASL 10, Florence, Italy

\subsection{6/annrheumdis-2001.305}

Background We evaluated sero-immunological parameters and markers of disease activity in ninety-two patients all female who underwent lip biopsy for histological assessment of sicca syndrome, according new preliminary criteria proposed for classification of Sjogren Syndrome (S. S).

Objectives The aim of our study was to compare the histopathological score index according to Chisolm and Mason classification with twenty-two parameters of disease activity.

Methods We have classified thirty-seven patients (group A) with focus score I-II with probable S. S (positivity of $3 / 6$ item) and fifty-five patients (group B) with focus score III-IV with defined S. $S$ (positivity of $4 / 6$ item). The mean age of two group was: group A $60 \pm 11$ years, group B $64 \pm 9.8$ years. The statistical comparison between the two group was performed with T-Student for 20 parameters and chi-square method for ANA and SSA/SSB positivity.

Results The comparison between the two groups show statistically significant differences for sero-immunological parameters such as gamma globulin $(\mathrm{p}<0.01)$, SSA/SSB $(\mathrm{p}<0.001)$. Moreover the group B shows higher levels of ESR $(p<0.005)$, fibrinogen $(\mathrm{p}<0.02)$ and alpha1-antitrypsin $(\mathrm{p}<0.005)$.

Conclusion This data show the important role of lip biopsy in the diagnosis of $S: S$ and suggest the possible correlation between high histopathologic focus score and immunological markers of disease activity.

\section{REFERENCES}

1 Vitali C, et al. Arthritis Rheum. 1992:36:340-8

2 Chisolm D, Mason D. J Clin Pathol. 1970;23: 690

\section{FRI0213 RAYNAUD'S PHENOMENON IN PRIMARY SJÖGREN'S SYNDROME. PREVALENCE AND CLINICAL CHARACTERISTICS IN A SERIES OF 320 PATIENTS}

${ }^{1} \mathrm{M}$ Garcia-Carrasco, 'M Ramos-Casals, ${ }^{2} \mathrm{~J}$ Rosas, ${ }^{1} \mathrm{~A}$ Siso, ${ }^{1} \mathrm{G}$ De la Red, ${ }^{1} \mathrm{O}$ Trejo, ${ }^{1} \mathrm{~V}$ Gil, ${ }^{1} \mathrm{R}$ Cervera, ${ }^{1} \mathrm{~J}$ Font, ${ }^{1} \mathrm{M}$ Ingelmo. 'Systemic Autoimmune Diseases Unit, Hospital Clinic, Barcelona; ${ }^{2}$ Rheumatology Unit, Hospital de Vilajoyosa, Vilajoyosa, Spain

\subsection{6/annrheumdis-2001.306}

\section{Background}

Objectives To determine the prevalence of Raynaud's phenomenon (RP) in a large series of patients with primary Sjögren's syndrome (SS) and to identify the clinical and immunological features related to its presence.

Methods In a cross-sectional study, we investigated 320 consecutive patients with primary SS (294 women and 26 men; mean age at onset 60 years; range 16-87 years). All patients fulfilled 4 or more of the diagnostic criteria for SS proposed by the European Community Study Group in 1993. Diagnosis of RP was done in SS patients with intermittent attacks of digital pallor and/or cyanosis, in the absence of any other associated disease or anatomical abnormalities.

Results Raynaud's phenomenon (RP) was present in 40 (13\%) patients. All were women, with a mean age of 57 years (range, 18 to 78 years). RP precedes onset of sicca symptomatology in 18 (45\%) patients. The main triggering factor was cold exposure, which induced RP in all patients, emotional stress in 12 and 2 patients had labour predisposition. Fifteen (38\%) patients required pharmacological treatment with calcium channel blockers (12 patients) or angiotensin-converting enzyme inhibitors (2 patients) in the cold seasons. One patient required treatment with intravenous prostacyclin for ischaemic complications. When compared with SS patients without RP, those with RP showed a higher prevalence of articular involvement $(50 \%$ vs $31 \%, \mathrm{p}=$ $0.031)$, cutaneous vasculitis $(30 \%$ vs $11 \%, \mathrm{p}=0.003)$, antinuclear antibodies $(95 \%$ vs $65 \%, \mathrm{p}<0.001)$, anti-Ro/SS-A $(59 \%$ vs $31 \%, \mathrm{p}<0.001)$ and anti-La/SS-B antibodies (44\% vs $20 \%$, p $=0.003$ ).

Conclusion We found RP in a $13 \%$ of patients with primary SS. Interestingly, RP was the first autoimmune symptomatology in almost $50 \%$ of these patients. These patients constituted a subset of SS with a higher frequency of some extraglandular features and positive immunological markers. In contrast, RP have a 